\title{
EXPERIMENTAL AUTOLOGOUS SUBSTITUTE VASCULAR GRAFT FOR TRANSPLANTATION SURGERY
}

\author{
L. Kóbori ${ }^{1 *}$, G. Dallos ${ }^{1}$, Anette S. H. Gouw ${ }^{2}$, T. Németh ${ }^{5}$, B. Nemes ${ }^{1}$, I. FehÉrVÁRI ${ }^{1}$, \\ A. M. Tegzess ${ }^{3}$, M. J. H. SloOfF ${ }^{4}$, F. PERner ${ }^{1}$ and K. P. DE JONG ${ }^{4}$ \\ ${ }^{1}$ Transplantation and Surgical Department, Semmelweis Medical University, H-1082 \\ Budapest, Baross u. 23-25, Hungary; ${ }^{2}$ Department of Pathology, ${ }^{3}$ Department of Ne- \\ phrology, ${ }^{4}$ Department of Hepatobiliary Surgery and Liver Transplantation, University \\ Hospital Groningen, Groningen, The Netherlands; ${ }^{5}$ Department of Surgery and Ophthal- \\ mology, Faculty of Veterinary Science, Szent István University, Budapest, Hungary
}

(Received November 5, 1999; accepted May 3, 2000)

\begin{abstract}
Vascular complications in liver transplantation are a major cause of graft failure and mortality. The aim of the study was to create autologous vascular graft without risk of rejection. Posterior rectus fascia sheath lined with peritoneum was used for iliac artery replacement in seven mongrel dogs. The patency was followed by palpation and Doppler ultrasound. The grafts were removed after one month. Five grafts remained patent. The Doppler showed good, relatively increased flow (median flow rate: $383 \mathrm{~cm} / \mathrm{sec}$ ) after one month in all of the cases. Slight increase in diameter was present in all cases. By microscopy the five patent grafts showed viable morphology, fibroblasts, smooth muscle cells and thin fibrin layer in the wall. The grafts were lined partially with a neoendothelial monolayer and a thin fibrin layer. In conclusion, this graft presents an acceptable patency rate and low thrombogenicity, and could be useful in transplantation. Further investigations are needed to study the effect of immunosuppression and rejection on long-term morphology and patency of the grafts.
\end{abstract}

Key words: Rectus fascia sheath, experimental vascular graft, liver transplantation

Vascular complications in liver transplantation are a major cause of graft failure and patient mortality. The most commonly reported arterial complications are acute and late thrombosis. The reported incidence ranges from 10 to $40 \%$ and is usually higher in paediatric recipients. Risk factors reported to be associated with hepatic artery thrombosis include small size of the artery, complicated arterial reconstructions and the use of arterial conduits (Hennein et al., 1993; Lallier et al., 1995; Lopez Santamaria et al., 1996). Portal vein thrombosis is reported in only 2 to $3 \%$ of recipients (Starzl et al., 1976). The incidence of stenosis or thrombosis of the vena cava after liver transplantation is lower than $1 \%$ (Lerut et al., 1987). Sometimes segments of iliac arteries and veins, harvested from heart-

*E-mail: kobori@mailtrans.sote.hu; Fax: +36 (1) 3170964 
beating donors, are used for arterial or portal reconstructions. The quality of these vessels is, however, often poor because of atherosclerosis, the effect of cold ischaemia and long preservation times. Furthermore, the diameter of these vessels can lead to a major size discrepancy. All these facts contribute to the occurrence of vascular thrombosis. These disadvantages can possibly be prevented by the use of autologous material from the recipient. Therefore, the technique of creating a tube of peritoneum-lined fascia, derived from the posterior rectus sheath first described by Cousar and Lam in 1952, was reinvestigated in an animal experiment. The aim of this study was to create a substitute vascular graft of autologous material and to examine the short-term patency and behaviour as an arterial interposition graft. Autologous posterior rectus fascia sheath (RS) lined with peritoneal mesothelial cells was used for external iliac artery replacement in seven mongrel dogs.

\section{Material and methods}

Seven mongrel dogs weighing 15 to $25 \mathrm{~kg}$ were used. The animals were treated according to the international guidelines for the care and use of laboratory animals (Declaration of Helsinki). 'Principles of laboratory animal care' (NIH publication No. 86-23, revised 1985) were followed and the specific national laws (current version of the Hungarian Act on the Humane Treatment and Protection of Animals) were applied. The animals were anaesthetised using pentobarbital sodium $(40 \mathrm{mg} / \mathrm{kg}$ ) and intratracheal anaesthesia with isoflurane (2 vol. $\%)$ and oxygen ( 2 litres/min). A median abdominal incision was made and the aorta bifurcation with the right external iliac artery was prepared and dissected from the surrounding tissues. After measurement of the diameter of the artery, one piece of $3 \times 4 \mathrm{~cm}$ was tailored from the RS (lined with peritoneum on the inside) and a $20 \mathrm{~mm}$ long tubular graft was created with running monofilament suture (Prolene 7/0, Ethicon). A glass tube (5 $\mathrm{mm}$ in diameter) was used as standard for forming the RS grafts. Before clamping the iliac artery, heparin was given (100 IU/ kg i.v.). After clamping, a $20-\mathrm{mm}$ segment of the artery was excised. The tube RS graft was interposed between the transected arterial ends and sewn into place with running monofilament suture (Prolene 7/0). After recirculation, the shape, patency, bleeding, pulsation and dilatation of the graft were monitored.

The abdomen was closed with running suture (Dexon 2/0, Davis-Geck) and the skin with Miralene (B. Braun). Heparin was given (Fragmin $7500 \mathrm{IU} /$ day s.c.) for two weeks followed by acetylsalicylic acid $(50 \mathrm{mg} /$ day) for two weeks. The follow-up of the animals was planned for one month. The patency of the graft was checked daily in the first week, and once weekly thereafter by palpation of the femoral pulse and by Doppler ultrasound examination (Brüel-Kjaer Medical, Panther 2002-5 MHz). After four weeks the animals were re-operated, 
the morphology, shape and patency of the grafts were inspected and the RS grafts were removed. The grafts were examined histologically using von Willebrand factor (vWf) expression technique to show the endothelial lining of the grafts.

\section{Results}

Five out of the seven grafts were patent after one month. In one case thrombosis occurred at day 7 due to infection and in another case at day 10 due to a technical failure (stenotic distal anastomosis).

The remaining five grafts were patent after one month. The femoral pulse was well palpable. Change in the median flow rate was calculated in all of the five cases after several Doppler examinations. A relative increase of the flow rate was detected in each animal. On the first postoperative day the median flow rate was $331 \mathrm{~cm} / \mathrm{sec}$ (ranges: $125-400 \mathrm{~cm} / \mathrm{sec}$ ) and after one month it was $383 \mathrm{~cm} / \mathrm{sec}$ (ranges: $200-500 \mathrm{~cm} / \mathrm{sec}$ ). Increase of the RS graft diameter was found in all cases. Average graft dilatation was $2.1 \mathrm{~mm}$ (ranges: 1.2-3.1 mm). No changes were found in the longitudinal size of these grafts. There were no signs of necrosis and no adhesions with the surrounding tissues. Gross examination of the five patent grafts showed viable tissues and an intact luminal surface even at the site of the anastomoses. Histological analysis of the RS grafts before implantation showed a normal structure of the rectus posterior sheath covered with peritoneum and islands of mesothelial cells. Microscopic examination of the five patent grafts showed intact and viable morphology with active fibroblasts and smooth muscle cells under the luminal surface. A thin fibrin layer was present in the graft wall. After one month no mesothelial cells were visible and all the removed patent grafts were lined partially (mean: $20 \%$ of the surface) with a neoendothelial monolayer and in the middle part with a thin fibrin layer (mean: $80 \%$ of the surface). Macrophage cells and granulocytes were present at the sites of the anastomoses without hypertrophy.

\section{Discussion}

The search for the ideal vascular substitute was started in 1906 by the use of venous and arterial replacements for arteries in dogs (Carrel and Guthrie, 1906). Goyannes was the first to use this technique in humans (Goyannes, 1906). Dubost et al. (1952) reported the initial success of an abdominal aortic replacement with preserved aortic homograft. De Bakey and Cooley (1953) and Szilagyi and Hemmer (1954) performed similar operations. Subsequent publications described degenerative changes such as necrosis and fibrosis in these grafts (Hoye and Warren, 1956). This problem stimulated the development of prosthetic vas- 
cular grafts (De Bakey et al., 1958). Ivalon, Orlon, Dacron, Teflon and polytetrafluorethylene (PTFE) were introduced for vascular replacements (Kempczinski, 1984). This new generation of vascular grafts had a lower incidence of complications such as prosthetic graft infection (Moore, 1984). This persistent incidence of complications stimulated new investigations for autogenous tissue grafts. In 1952, Cousar and Lam reported a series of canine experiments, using the posterior rectus fascia peritoneum sheath (RS) for aortic patch repair and tube graft replacements (Cousar and Lam, 1952). Kehne and Sensenig (1956) and Holdefer et al. (1968) reported cases with RS for vascular repair complicated with aneurysmal dilatations. The RS was used in cardiac surgery in congenital heart defects and pericardial reconstructions (Anagnostopoulos et al., 1995). It was also used for venous substitutes in experimental and clinical medicine (Louagie et al., 1986). Experimental and clinical studies with RS in vascular and cardiac surgery showed good long-term (3-72 months) results (Bilfinger et al., 1983; Coltharp, 1989; Anagnostopoulos et al., 1995). The RS grafts were generally lined with a neoendothelial layer after three months and even presented growth comparable to the aorta (Bilfinger et al., 1983; Coltharp, 1989). In transplantation surgery, especially in liver transplantation, sometimes difficulties are encountered during vascular reconstructions. The results obtained with different vascular grafts, like the donor iliac artery, are controversial. Cyclosporine A delays intimal hyperplasia but this favourable effect is possibly abolished by ultrastructural changes in the vessel wall (Bujan et al., 1995; Bellon et al., 1996). The chronic rejection in transplanted organs results in progressive thickening of the vessel wall due to neointimal hyperplasia. Experimental studies have shown that one of the causes of these changes is the phenotypic change of the vascular smooth muscle cells and the alteration of their function (Geraghty et al., 1996).

Therefore, we reinvestigated the use of fresh, non-preserved and autologous RS grafts. The method used in this study demonstrates that the RS graft can be used for vascular replacement. The patency was acceptable after one month and the histological examination showed viable tissue. The relatively low thrombogenicity was due to the presence of mesothelial and neoendothelial layers in the grafts. In the two cases with thrombosis the cause was infection and technical complication. Graft dilatation occurred in all of the cases, but the patency index was good and no thrombosis occurred in five cases. Additional studies are needed to determine the long-term course of such dilatation of the RS graft and its effect on wall strength. Preparation of the RS graft is not difficult and not expensive. Such grafts are not damaged by preservation or storage solutions.

In this preliminary study we found that a strip of peritoneum-lined rectus fascia is able to function as an arterial interposition graft. The use of atraumatic techniques can reduce the incidence of technical problems like thrombosis and infection. There is histological evidence that the mesothelial lining of this graft is replaced by endothelial cells. This autologous graft presents an acceptable pat- 
ency rate and could be useful as an arterial substitute in transplantation surgery. Further investigations are needed to study the effect of immunosuppression and rejection periods on the long-term morphology and patency of this autologous graft.

\section{References}

Anagnostopoulos, C. E., Connery, C. P., Bilfinger, T. V., Seifert, F., Hartman, A., Biancaniello, T., Azariades, P. and Agorogiannis, S. (1995): Initial clinical experience with rectus sheath grafts in congenital heart defects. J. Cardiovasc. Surg. Torino 36, 429-432.

Bellon, J. M., Bujan, J., Jurado, F., Hernando, A., Honduvilla, N. G. and Dominguez, B. (1996): Cyclosporine A delays the presentation of intimal hyperplasia in an experimental model of arterial autograft. Eur. Surg. Res. 28, 39-48.

Bilfinger, T. V., Beere, P. E., Sanderson, C., Glagov, S. and Anagnostopoulos, C. E. (1983): Parallel growth of rectus sheath grafts and recipient aorta. Critical role of graft tissue preservation. J. Thorac. Cardiovasc. Surg. 86, 294-299.

Bujan, J., Bellon, J. M., Jurado, F., Hernando, A. and Contreras, L. (1995): Assessment of cyclosporine A-induced ultrastructural changes in vascular wall using an experimental arterial autograft model. Histol. Histopathol. 10, 567-576.

Carrel, A. and Guthrie, C. G. (1906): Uniterminal and biterminal venous transplantations. Surg. Gynecol. Obstet. 2, 266-270.

Coltharp, W. H. (1989): Experimental aortic replacement with a vascularized tissue graft. Arch. Surg. 124, 1331-1334.

Cousar, J. E. and Lam, C. R. (1952): Rectus sheath grafts in vascular repair. Arch. Surg. 65, 471-476.

De Bakey, M. E. and Cooley, D. A. (1953): Surgical treatment of aneurysm of abdominal aorta by resection and restoration of continuity with homograft. Surg. Gynecol. Obstet. 97, 257-266.

De Bakey, M. E., Cooley, D. A. and Crawford, S. (1958): Clinical application of a new flexible knitted Dacron arterial substitute. Am. Surg. 24, 862-869.

Dubost, C., Allary, M. and Oeconomos, N. (1952): Resection of an aneurysm of the abdominal aorta. Arch. Surg. 64, 405-408.

Geraghty, J. G., Stoltenberg, R. L., Sollinger, H. W. and Hullett, D. A. (1996): Vascular smooth muscle cells and neointimal hyperplasia in chronic transplant rejection. Transplantation $\mathbf{6 2}$, 502-509.

Goyannes, D. J. (1906): Plastic substitution of arteries and veins, application of venous arterioplasty, the new method in the treatment of aneurysms (in Spanish). J. El. Siglo Medico 53, 546-561.

Hennein, H. A., Mendeloff, E. N., Turcotte, J. G., Ham, J. M., Baliga, P., Campbell, D. A. Jr. and Merion, R. M. (1993): Aortic revascularization of orthotopic liver allografts: indications and long term follow up. Surgery 113, 279-285.

Holdefer, W. F., Edwards, S. and Dowling, E. R. (1968): Autologous rectus fascia as an arterial replacement. Arch. Surg. 97, 124-127.

Hoye, S. J. and Warren, R. (1956): Follow up studies of iliofemoral arterial reconstruction in arteriosclerosis obliterans. N. Engl. J. Med. 254, 102-106.

Kehne, J. H. and Sensenig, D. M. (1956): Arterial replacement with rectus fascia. Arch. Surg. 72, 516-519.

Kempczinski, R. F. (1984): Vascular grafts - an overview. In: Rutherford, R. B. (ed.) Vascular Surgery. W. B. Saunders Co., Philadelphia. pp. 361-366.

Lallier, M., St. Vil, D., Dubois, J., Paradis, K., Laberge, J. M., Bensoussan, A. L., Guttman, F. M. and Blanchard, H. (1995): Vascular complications after pediatric liver transplantation. J. Pediatr. Surg. 30, 1122-1126. 
Lerut, J., Tzakis, A. G. and Bron, K. (1987): Complications of venous reconstruction in human orthotopic liver transplantation. Ann. Surg. 205, 404-414.

Lopez Santamaria, M., Vazquez, J., Gamez, M., Murcia, J., Bueno, J., Martinez, L., Paz Cruz, J. A., Reinoso, F., Bourgeois, P., Diaz, M. C., Hierro, L., Camarena, C., de la Vega, A., Frauca, E., Jara, P. and Tovar, J. A. (1996): Donor vascular grafts for arterial reconstruction in pediatric liver transplantation. J. Pediatr. Surg. 31, 600-603.

Louagie, Y., Legrand Monsieur, A., Remacle, C., Maldague, P., Lambotte, L. and Ponlot, R. (1986): Morphology and fibrinolytic activity of canine autogenous mesothelium used as venous substitute. Res. Exp. Med. Berl. 186, 239-247.

Moore, W. S. (1984): Infection in prosthetic vascular grafts. In: Rutherford, R. B. (ed.) Vascular Surgery. W. B. Saunders Co., Philadelphia. pp. 413-424.

Starzl, T. E., Porter, K. A., Putnam, C. W., Schroter, G. P., Halgrimson, C. G., Weil, R., Hoelscher, M. and Reid, H. A. (1976): Orthotopic liver transplantation in ninety-three patients. Surg. Gynecol. Obstet. 142, 49-53.

Szilagyi, D. E. and Hemmer, J. A. (1954): Resection of aortic bifurcation and replacement with homologous graft for aneurysm. JAMA 154, 751-753. 